\title{
Do Recent Trends in RA Surgery Reflect Success in Disease Management?
}

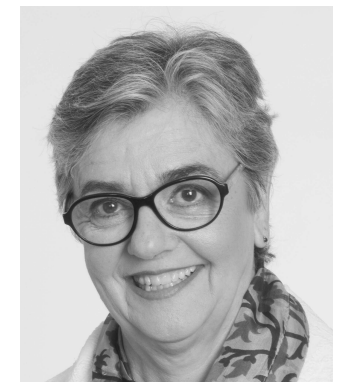

Longterm outcomes are critically important for patients living with a chronic disease such as rheumatoid arthritis (RA). Because joints are replaced for endstage damage to the target organ in RA, studies that identify changes in the use of arthroplasty provide insight into changes in longterm RA outcomes. In this issue of The Journal, Young and colleagues ${ }^{1}$ studied arthroplasties to evaluate use trends for patients with RA.

The investigators used data from the National Inpatient Sample (NIS), the largest US all-payer inpatient database, which contains a sample of over 1000 hospitals in the United States participating in the Healthcare Cost and Utilization Project. They assessed trends in the proportion of patients with RA among arthroplasty patients undergoing total shoulder (TSA), elbow (TEA), knee (TKA), hip (THA), and ankle (TAA) arthroplasty between 2002 and 2012. They determined the incidence of arthroplasties based on the US population, and compared the data from the first year of the study, 2002, to the final year, 2012. While studies using large databases such as the NIS have strengths and weaknesses, the large numbers contained in this database permit recognition of surgical trends and can be used to assess trends in less frequently performed procedures such as TAA or TEA. However, relevant data such as disease severity, presence of erosions, or medication use are not available, and coding errors or misclassification may occur. The investigators note, however, that because misclassification is unlikely to change over time, the effect on a study of time trends may not be significant. Their observations describe the change in the proportion of patients with RA undergoing the procedures of interest; therefore, it cannot be determined whether the use pattern for patients with RA has changed or whether the indications for and use of the procedures have changed for those without RA. And while their study was not designed to specifically assess the evolution of the disease or treatment over time, their well-designed observations are thought-provoking.

The investigators found that there was a significant increase in arthroplasty use overall in the general population, and the overall proportion of patients with RA among those undergoing arthroplasty has remained stable. However, for patients with RA, there were significant decreases in replacements for specific joints. The proportion of patients with RA undergoing TEA decreased by $50 \%$, TSA by $18 \%$, and TAA by $38 \%$. For TKA and THA, which are the most frequently performed arthroplasty procedures, the proportion with RA increased slightly. In addition, the average age for patients with RA at the time they undergo arthroplasty has risen, while the age for those undergoing arthroplasty in the general population has decreased. Women with RA had a greater decrease in the rates of TSA, TEA, and TAA than men did. When race was analyzed, additional differences emerged. For white patients with RA, there was a decrease in TSA, TEA, and TAA, but for black patients with RA, the pattern was mixed. The percent of black patients undergoing TAA decreased, the percent undergoing TEA increased, and the percent of blacks with RA undergoing TSA was unchanged. Differences also emerged when comparing patients with (government-sponsored) Medicaid versus private insurance. The proportion of patients with RA with private insurance who underwent TSA and TAA decreased, while the proportion of patients with Medicaid undergoing TSA, TEA, and TAA remained unchanged.

If the need for arthroplasty for patients with RA represents severe disease and failed medical therapy, do decreasing arthroplasty rates indicate overall success, and if so, what does the difference in use trends among joints indicate? Previous reports have demonstrated that patients enrolled in RA inception cohorts with maximally 25 years of followup were less likely to undergo hand/foot surgery over time, but the rate of large joint procedures including THA and TKA was unchanged, concurrent with the increased use of combination disease-modifying antirheumatic drugs and biologic therapy $^{2}$. The decreased rate of replacements of more "RA-specific" joints - the ankle, elbow, and shoulder may indicate that different joints respond differently to therapy, a possibility suggested by evidence of joint-specific genetic signatures that may potentially determine treatment response $^{3}$. However, other studies have identified risk factors for arthroplasty for patients with RA and noted classic

See Joint replacement surgery in RA, page 158

Personal non-commercial use only. The Journal of Rheumatology Copyright $\subset$ $\subset$ 2018. All rights reserved. 
indicators of severity including erosions, seropositivity, and disease activity 4,5 . For the majority of patients undergoing arthroplasty for RA, there is good news in this paper, demonstrating a significant decline in the prevalence of RA among arthroplasty patients. Elbow arthritis is usually due to RA, and $79 \%$ of TEA are performed for RA, so the dramatic decline in TEA may be a bellwether indicating that RA is now less severe or better managed, and therefore less likely to progress to an endstage joint ${ }^{6}$. In fact, while the widespread use of biologics has been clearly related to decreases in RA structural damage, improvement in RA status was seen prior to the widespread use of biologics, and was associated with more aggressive treatment strategies and with earlier referral and less delay in initiation of therapy, but not specific medications $7,8,9,10$. Others have demonstrated that use of biologics has not decreased the use of arthroplasty, although use of methotrexate may ${ }^{11,12}$.

The good news in this paper for whites with RA is tempered by the mixed news for blacks and those with Medicaid insurance, suggesting that disparities in healthcare for blacks may be getting worse. Is there a difference in the severity of RA in blacks that could explain this disparity? Blacks followed in an early RA longitudinal registry have early damage and erosions, similar to other early arthritis cohorts ${ }^{13}$. While disease activity improved over time for both blacks and whites in a large US registry, blacks maintained higher disease activity than whites and were less likely to achieve remission, and disease activity is clearly associated with progression to damage requiring arthroplasty ${ }^{5,14}$. Blacks and those with Medicaid insurance are less likely to receive biologic therapy, or they receive it later in the course of disease ${ }^{15,16,17}$. However, other studies have shown that blacks prefer less aggressive therapy than whites for RA and prioritize risk over efficacy ${ }^{18}$. Further confounding a simple analysis of the effect of social factors on health is a report revealing that while patients with RA treated at a university clinic had better function and disease activity overall compared to patients treated in a public county hospital clinic, white patients at the university clinic had better outcomes and were more likely to receive biologics than nonwhites, while there was no racial disparity in the poorer scores seen at the county clinic ${ }^{19}$.

While the improved outcomes for RA reflected in decreasing elbow, ankle, and shoulder replacement reported here probably reflect early diagnosis, referral, and the widespread acceptance of early aggressive therapy, the challenge now is to improve the application of these strategies to all patients with RA. The difference in arthroplasty use among blacks and whites and those with Medicaid insurance suggests it is not changes in the natural course of $\mathrm{RA}$, but rather changes in treatment and management strategies that have led to improved outcomes. However, social factors such as race and poverty still affect healthcare delivery and treatment success ${ }^{20}$.
SUSAN M. GOODMAN, MD,

Attending Rheumatologist, Division of Rheumatology, Hospital for Special Surgery, Professor of Clinical Medicine, Department of Medicine, Weill Cornell Medical School, New York, New York, USA

Address correspondence to Dr. S.M. Goodman, 535 East 70th St., New York, New York 10021, USA. E-mail: Goodmans@hss.edu

\section{REFERENCES}

1. Young BL, Ponce BA, Watson SL, Perez JL, McGwin G, Singh JA. Trends in joint replacement surgery in patients with rheumatoid arthritis. J Rheumatol 2018;45:158-64.

2. Nikiphorou E, Carpenter L, Morris S, Macgregor AJ, Dixey J, Kiely $\mathrm{P}$, et al. Hand and foot surgery rates in rheumatoid arthritis have declined from 1986 to 2011, but large-joint replacement rates remain unchanged: results from two UK inception cohorts. Arthritis Rheumatol 2014;66:1081-9.

3. Ai R, Hammaker D, Boyle DL, Morgan R, Walsh AM, Fan S, et al. Joint-specific DNA methylation and transcriptome signatures in rheumatoid arthritis identify distinct pathogenic processes. Nat Commun 2016;7:11849.

4. Kapetanovic MC, Lindqvist E, Saxne T, Eberhardt K. Orthopaedic surgery in patients with rheumatoid arthritis over 20 years: prevalence and predictive factors of large joint replacement. Ann Rheum Dis 2008;67:1412-6.

5. Nikiphorou E, Norton S, Young A, Carpenter L, Dixey J, Walsh DA, et al. Association between rheumatoid arthritis disease activity, progression of functional limitation and long-term risk of orthopaedic surgery: combined analysis of two prospective cohorts supports EULAR treat to target DAS thresholds. Ann Rheum Dis 2016;75:2080-6.

6. Jenkins PJ, Watts AC, Norwood T, Duckworth AD, Rymaszewski LA, McEachan JE. Total elbow replacement: outcome of 1,146 arthroplasties from the Scottish Arthroplasty Project. Acta Orthop 2013;84:119-23.

7. Irvine S, Munro R, Porter D. Early referral, diagnosis, and treatment of rheumatoid arthritis: evidence for changing medical practice. Ann Rheum Dis 1999;58:510-3.

8. Finckh A, Choi HK, Wolfe F. Progression of radiographic joint damage in different eras: trends towards milder disease in rheumatoid arthritis are attributable to improved treatment. Ann Rheum Dis 2006;65:1192-7.

9. Ciubotariu E, Gabay C, Finckh A, Physicians of the Swiss Clinical Quality Management Program for Rheumatoid Arthritis. Joint damage progression in patients with rheumatoid arthritis in clinical remission: do biologics perform better than synthetic antirheumatic drugs? J Rheumatol 2014;41:1576-82.

10. Pincus T, Sokka T, Kautiainen H. Patients seen for standard rheumatoid arthritis care have significantly better articular, radiographic, laboratory, and functional status in 2000 than in 1985. Arthritis Rheum 2005;52:1009-19.

11. Aaltonen KJ, Virkki LM, Jamsen E, Sokka T, Konttinen YT, Peltomaa R, et al. Do biologic drugs affect the need for and outcome of joint replacements in patients with rheumatoid arthritis? A register-based study. Semin Arthritis Rheum 2013;43:55-62.

12. Asai S, Kojima T, Oguchi T, Kaneko A, Hirano Y, Yabe Y, et al. Effects of concomitant methotrexate on large joint replacement in patients with rheumatoid arthritis treated with tumor necrosis factor inhibitors: a multicenter retrospective cohort study in Japan. Arthritis Care Res 2015;67:1363-70.

Personal non-commercial use only. The Journal of Rheumatology Copyright @ 2018. All rights reserved. 
13. Bridges SL Jr, Causey ZL, Burgos PI, Huynh BQ, Hughes LB, Danila MI, et al. Radiographic severity of rheumatoid arthritis in African Americans: results from a multicenter observational study. Arthritis Care Res 2010;62:624-31.

14. Greenberg JD, Spruill TM, Shan Y, Reed G, Kremer JM, Potter J, et al. Racial and ethnic disparities in disease activity in patients with rheumatoid arthritis. Am J Med 2013;126:1089-98.

15. Suarez-Almazor ME, Berrios-Rivera JP, Cox V, Janssen NM, Marcus DM, Sessoms S. Initiation of disease-modifying antirheumatic drug therapy in minority and disadvantaged patients with rheumatoid arthritis. J Rheumatol 2007;34:2400-7.

16. Kerr GS, Swearingen C, Mikuls TR, Yazici Y. Use of biologic therapy in racial minorities with rheumatoid arthritis from 2 US health care systems. J Clin Rheumatol 2017;23:12-8.

17. Chu LH, Portugal C, Kawatkar AA, Stohl W, Nichol MB.
Racial/ethnic differences in the use of biologic disease-modifying antirheumatic drugs among California Medicaid rheumatoid arthritis patients. Arthritis Care Res 2013;65:299-303.

18. Constantinescu F, Goucher S, Weinstein A, Fraenkel L. Racial disparities in treatment preferences for rheumatoid arthritis. Med Care 2009;47:350-5.

19. Barton JL, Trupin L, Schillinger D, Gansky SA, Tonner C, Margaretten M, et al. Racial and ethnic disparities in disease activity and function among persons with rheumatoid arthritis from university-affiliated clinics. Arthritis Care Res 2011;63:1238-46.

20. Uhlig T, Kvien TK. Is rheumatoid arthritis really getting less severe? Nat Rev Rheumatol 2009;5:461-4.

J Rheumatol 2018;45:147-9; doi:10.3899/jrheum.171056 